\title{
The need of Social Science and Community approaches in Human Nutrition in Tertiary Education
}

Christopher Papandreou*

Preventive Medicine and Nutrition Clinic, University of Crete, School of Medicine, P.O.B. 2208 GR-71003, Heraklion, Crete, Greece

\section{Introduction}

Human Nutrition entails the study of the food-depended growth, maintenance and repair of the body, and comprises a necessary component of tertiary education in health. Human Nutrition science has received special attention over the past three decades, although adequate nutrition instruction is not always provided in universities or is not provided within designated Nutrition courses [1,2]. Nutrition is coming to the fore as a major modifiable determinant of chronic disease, with scientific evidence increasingly supporting the view that alterations in diet have strong effects, both positive and negative, on health throughout all human life.

Most importantly, dietary adjustments may not only influence present health, but may determine whether or not an individual will develop such diseases as obesity, diabetes, cardiovascular disease, several forms of cancer, osteoporosis and dementia much later in life. These chronic diseases are burdening the health in both developed and developing countries. Therefore, there is a need of community based recommendations for nutrition, and social science approaches, in the prevention of chronic diseases.

\section{Community nutrition}

Nutritional sciences are based on levels of organizational complexity from molecules through metabolism to populations [3]. NutritionDietetics application, as well as nutrition education of consumers, needs to address food preferences and sensory-affective factors; person related factors such as perceptions, beliefs, attitudes, meanings, and social norms; and environmental factors [4]. Community nutrition [5] is the process of helping individuals and groups develop healthy eating habits in order to promote wellness and prevent the side effects of chronic disease. The goal of community nutrition is to educate people from all age groups so that they adopt healthy eating habits.

Nutritionists work with many other health care professionals in promoting improved community nutrition. Their efforts emphasize a preventive approach in educating individuals in how a change in dietary habits will reduce the risk of illness. Concerning the promotion of health and prevention of nutritional diseases in the community level, it includes activities on nutrition education, health promotion, food quality programs, supplementation programs (i.e. fluoride, folic acid, iodine, iron etc.), preventive programs, local policy analysis and development. Community nutrition involves application of socialscience as well as psychological, cultural, agricultural, economic, clinical, and public health policy methods for working with groups and populations [5].

\section{Social Science approaches}

As stated by Pelto and Freake [3]: "The need to incorporate social science approaches in nutrition is apparent when the limitations of an exclusive focus on biological approaches are examined. For example, despite great advances in our knowledge about the metabolic and molecular pathways that govern energy metabolism and food intake, the incidence of obesity continues to rise to epidemic proportions. Biological knowledge, alone, is inadequate to understand this phenomenon and its consequences". Social, as well as economic, factors lead to particular nutritional outcomes [3]; consequently subjects as, political economy of food and nutrition; children nutritional awareness; television and advertisement effects on food preferences; immigration effects; modern lifestyle effects etc, have to be researched and included in tertiary education.

\section{Conclusion}

The American Society for Nutritional Sciences (A.S.N.S) Graduate Nutrition Education Committee suggests that three major challenges face the nutritional sciences: (a) to train doctoral students to be full and active participants in interdisciplinary research and discovery, and (b) to achieve this goal while maintaining nutrition's unique academic identity and (c) fostering a cohesive academic community [6]. As we enter the second decade of the 21st century, nutrition is further recognized as a major parameter of human wellbeing, quality of life, and disease prevention. The most exciting academic challenges and employment opportunities for nutritional sciences graduates interface with other disciplines [6]: Nutrition-Dietetics applications have to do with individual persons and with populations, thus, the social dimensions have to be taken into account and studied in depth. In addition to the dieticians, other specialists are and must further be involved in teaching various aspects of nutrition, including biochemists, pharmacists, pharmacologists, physiologists, psychologists, sociologists, and of course various medical doctors of various specialties [7]. The selection of new courses, and lessons descriptions, remains a challenge that may be faced knowledgeably, under the demand to discriminate the important and fruitful from the simply impressive and/or unproductive.

\section{References}

1. Adams KM, Lindell KC, Kohlmeier M, Zeisel SH (2006) Status of nutrition education in medical schools. Am J Clin Nutr: 941S-944S.

2. Kafatos $A$ (2009) Is clinical nutrition teaching needed in medical schools? Ann Nutr Metab 54: 129-130.

*Corresponding author: Christopher Papandreou, Preventive Medicine and Nutrition Clinic, University of Crete, School of Medicine, P.O.B. 2208 GR-71003, Heraklion, Crete, Greece, Tel: +30 6974303995; E-mail: papchris10@gmail.com

Received December 23, 2011; Accepted December 23, 2011; Published December 26, 2011

Citation: Papandreou C (2011) The need of Social Science and Community approaches in Human Nutrition in Tertiary Education. J Socialomics 1:e103. doi:10.4172/2167-0358.1000e103

Copyright: @ 2011 Papandreou C. This is an open-access article distributed under the terms of the Creative Commons Attribution License, which permits unrestricted use, distribution, and reproduction in any medium, provided the original author and source are credited. 
Citation: Papandreou C (2011) The need of Social Science and Community approaches in Human Nutrition in Tertiary Education. J Socialomics 1:e103. doi:10.4172/2167-0358.1000e103

Page 2 of 2

3. Pelto GH, Freake $\mathrm{CH}$ (2003) Social Research in an Integrated Science of Nutrition: Future Directions. J Nutr 133: 1231-1234.

4. Contento IR (2008) Nutrition education: linking research, theory, and practice. Asia Pac J Clin Nutr 17: 176-179.

5. Nweze E. Nnakwe (2008) Community Nutrition: Planning Health Promotion and Disease Prevention, Jones \& Bartlett Learning Publishers, USA.
6. Allen LH, Bentley ME, Donovan SM, Ney DM, Stover PJ (2002) Securing the future of nutritional sciences through integrative graduate education. J Nutr 132: 779-784.

7. Bender DA (1995) Nutrition in the curriculum for health-care professionals. Environmental Management and Health 6: 14-16. 